\title{
Pro-environmental habits: An underexplored research agenda in sustainability science
}

\author{
Noah Linder (1), Matteo Giusti, Karl Samuelsson, Stephan Barthel
}

Received: 3 March 2021/Revised: 16 July 2021 / Accepted: 18 August 2021/Published online: 14 September 2021

\begin{abstract}
Habits are the fundamental basis for many of our daily actions and can be powerful barriers to behavioural change. Still, habits are not included in most narratives, theories, and interventions applied to sustainable behaviour. One reason societies struggle to reach policy goals and people fail to change towards more proenvironmental lifestyles might be that many behaviours are now bound by strong habits that override knowledge and intentions to act. In this perspective article, we provide three arguments for why pro-environmental habits are a needed research agenda in sustainability science: (1) habit theory highlights how behaviour is heavily reliant on automatic processes, (2) the environmental context sets boundary conditions for behaviour, shape habits, and cues action responses, and (3) our habits and past behaviour shape our values and self-identity. These arguments highlight the transformative potential of looking at sustainable behaviours through a habit lens. We believe a research agenda on pro-environmental habits could generate a more holistic understanding of sustainable behaviours and complement today's dominating approaches which emphasize reasoned decisions and intrinsic motivations such as values, norms, and intentions to understand and predict pro-environmental behaviour. We highlight evident knowledge gaps and practical benefits of considering habit theory to promote pro-environmental behaviours, and how habit architecture could be utilized as a strong leverage point when designing, modifying, and building urban environments.
\end{abstract}

Keywords Behaviour change - Climate change ·

Habit · Pro-environmental behaviour · Urban sustainability

\section{INTRODUCTION}

Human behaviour is at the root of most environmental challenges we face today. To reach sustainability targets and ensure a safe operating space for humanity on earth, rapid behaviour changes are needed across scales ranging from individuals to leaders on all levels of society (Steffen et al. 2015; UN General Assembly 2015). Promisingly, pro-environmental values seem to grow stronger every day (Bouman and Steg 2019; Manfredo et al. 2020) and recent reports indicate that more than $60 \%$ of people across the world now acknowledge the climate crisis (Flynn et al. 2021). Yet, a significant shift towards sustainable lifestyles have not been observed (IPCC 2014; Brondizio et al. 2019). One reason many struggle to change might be that several environmentally damaging behaviours are by now bound by habits that can be strong enough to continuously override new knowledge and intentions (Verplanken 2018). Habits are the fundamental basis for many daily actions and can be powerful barriers to change, once habits take shape they persist without much deliberation or re-consideration (Wood and Rünger 2016). It is therefore not only the decisions that we make today that form the wide foundation of our unsustainable behaviours, but the decisions we once took that are now solidified in strong habits and lifestyles.

However, the impact of habits is seldom accounted for in studies on pro-environmental behaviour, which instead often emphasize the role of values, norms, attitudes, intentions, and motivation for pro-environmental behaviour (Schultz and Kaiser 2012; Sörqvist 2016). Correspondingly, most interventions aiming to ignite sustainable transformations are focussed on building intrinsic 
motivation through rational processes like knowledge building, feedback, and monitoring-which are likely not powerful enough to break habits and create long-term behavioural change (Verplanken 2018). Attitude-behaviour models (e.g. theory of planned behaviour and value belief norm theory) have been the dominating lens through which to study pro-environmental behaviour and they have shown to be pragmatic and effective, explaining around $20-30 \%$ of the variance in human behaviour despite inherent vast complexities involved (see e.g. McEachan et al. 2016). However, they seldom paint the full picture and people often fail to align knowledge and internal motivations with sustainable actions (Kollmuss and Agyeman 2002; Steg and Vlek 2009). Such value/attitudeaction gaps (Blake 1999) mean that even though an individual possesses intrinsic motivation she will not necessarily manifest such motivational drive in proenvironmental behaviours. Some studies have even shown the opposite to be true. For example, households of higher socio-economic status often report strong pro-environmental values and relatively higher ecological knowledge, while at the same time energy consumption is strongly correlated with house size, a key indicator of socio-economic class (Jackson 2004).

Habits seem to be largely neglected within the field of sustainability science, even though they have been highlighted as a potential barrier for aligning intrinsic motivation with sustainable behaviour changes (Verplanken et al. 1998; Kollmuss and Agyeman 2002; Jackson 2004), and as setting boundary conditions for the validity of attitudebehaviour models (Verplanken and Aarts 1999). A Scopus search undertaken on 26 January 2021 showed that in the vast amount of research addressing sustainability (596 653 articles), ${ }^{1}$ less than $0.5 \%$ articulate habits in the title, abstract, or keywords. In the research explicitly addressing pro-environmental behaviour (2719 articles), ${ }^{2}$ only about $3 \%$ of the articles address habits. A closer look at the latter search revealed that most of these articles either only briefly mention habit, use habits to simply refer to behaviour or as a measure of repeated past behaviours. Some efforts have been made to expand attitude-behaviour models by including habits, often increasing the predictive power (e.g. Donald et al. 2014; Chuang et al. 2018; Bell and Ulhas 2020; Çoker and van der Linden 2020; Liu et al. 2020; Aboelmaged 2021). Others call for more research on habits (Peattie 2010; Wynes et al. 2018) or highlighting habits as a strong barrier/motivator for pro-environmental behaviours (e.g. Dharmesti et al. 2020; Huang et al. 2020; Russell and Knoeri 2020), and still some others draw on

\footnotetext{
${ }^{1}$ Search phrase used: "sustainab* AND Habit".

2 "Pro-environmental behavi* OR Proenvironmental behavi* AND Habit”.
}

habit theory when designing behaviour-specific interventions (Staats et al. 2004; Winter and Burn 2010; Ro et al. 2017; Heidbreder et al. 2020). We only found a few articles addressing the roles of habits for sustainability transformations. For example, White et al. (2019) include habits in a framework for designing interventions to promote sustainability transformations and Dahlstrand and Biel (1997) highlight different propensity levels for shifts towards sustainable behaviour depending on the strength of habits. Within the scope of this article, we limited the Scopus search to "pro-environmental behaviour". It is possible, however, that habits are also considered in conjunction with other terms, not captured in this search, such as "green behaviour", "sustainable behaviour", or specific behaviours such as "recycling". Nevertheless, our search indicates a seeming lack of scientific interest in the role of habits in relation to sustainable actions from most scholars. This is surprising considering the powerful influence habit can have on behaviours that must radically change in the near future.

This paper aims to explore the potential habits may have for igniting (or hindering) transformations towards sustainable behaviours. We define Pro-Environmental Habits $(\mathrm{PEH})$ as "habits that either benefit the environment or harms it as little as possible" (based on the Steg and Vlek (2009) definition of pro-environmental behaviour). We start by giving an account of the existing theories and research on habits. We then discuss habits in relation to pro-environmental behaviours and articulate three arguments for why research on $\mathrm{PEH}$ may be a needed research agenda for sustainability science. We discuss implications, research gaps, and argue for the potential of focussing more on breaking habits and on building PEH when designing and modifying the built environment.

\section{OUR RELIANCE ON HABITS}

In our daily lives, we develop habits through repeating actions in stable contexts, which then become efficient, default modes of responses-persisting with little guidance, intentions, or deliberate thought (Gardner 2015; Wood and Rünger 2016). Habits guide many decisions, with one study looking at hourly self-reported behaviour records estimating that about $40 \%$ of all our daily behaviours are guided by habit without conscious deliberation (Wood et al. 2002). This is likely a low estimate considering that self-reported measures struggle to fully capture automatic behaviours. Habits and other automatic processes often remain understudied since they are inherently hard to measure (Rebar et al. 2018) and can require expensive longitudinal analysis (Gardner 2015). It might be hard to estimate exactly how much of our behaviour is 
governed by habits, but it is safe to say that habits guide many of our daily actions.

Our reliance on habits is not that surprising considering how they free up working memory and enable us to save time and multi-task (Wood and Rünger 2016). Habits can motivate us to act when we are low on willpower, stressed, or not able to deliberate on responses (Mazar and Wood 2018). Habitual knowledge is also stable and protected from short-term whims or random events, and can provide pre-determined action responses or mental solutions to recurring complex problems (Wood and Rünger 2016). Habits can even be seen as our brain's way of outsourcing action control to environmental cues, which provides us with a ready response to familiar situations (ibid). Reliance on habits is logical from an evolutionarily perspective, as we are evolved to preserve time and energy and the use of cognitive attention and working memory is both energydraining and time-consuming (Epstein 1994). In addition to habits, we also use e.g. heuristics (mental rules of thumb), norms, and emotions to help guide actions without much need for deliberation (Strack and Deutsch 2004). Such fast, automatic, intuitive, and energy-efficient ways of handling information or acting on stimuli have been conceptualized as being part of a "system 1" or the "impulsive" system. "System 2" or the "reflective" system on the other hand is our slow, deliberate, conscious, and more energy draining system (ibid.).

It is not always the case that relying on our impulsive system is working to our advantage. Problems arise when we, for example, develop unwanted habits that are hard to break, our heuristics systematically arrive at wrong or biassed conclusions or when we respond to our emotions with regretful actions. One reason habits are fundamentally difficult to "un-do" is that they are controlled by different neural networks compared to intention-driven behaviour: after a habit is established the behaviour should no longer be considered goal-directed (Miller et al. 2019) and tends to persist whether we want it to or not. As Nathaniel Emmons put it: "Habit is either the best of servants or the worst of masters" (Edwards 1891, p. 212). Only through effortful goal pursuits, for example when the habit proves unreliable in a given context or when people are especially motivated and able to tailor responses to particular circumstances, do we sometimes manage to change. However, seeing how willpower fluctuates over time, motivation alone often fails to change established habits. Various factors such as time pressure, distraction, stress, hunger, and addiction impede people's ability to deliberate and consciously choose their actions, thus tipping the balance back towards established automatic habits (Verplanken 2018).

\section{Habit theory, formation, and mechanisms}

Habits are commonly used in the literature without a clear definition (Southerton 2013), often used simply as a measure of repeated past behaviour (Verplanken 2018). However, three key pillars are constituting habits: they need repetition to form, they direct behaviour automatically, and they are context-dependent (e.g. Kurz et al. 2015). Hence, habits can be defined as "memory-based propensities to respond automatically to specific cues, which are acquired by the repetition of cue-specific behaviour in stable contexts" (Verplanken 2018, p. 4). It is important to note here that habits are also explored from different perspectives in the literature and that there is still some unanswered questions and disagreements about what habits are. For example, social practice scientists would not recognize habits through context-cued automaticity. Instead, they look at habit without separating the individual and the context and see habits as constantly unfolding actions, an integrated part of social processes and complex dynamics (Kurz et al. 2015). In this paper, we take a psychological perspective on habits using the definition from Verplanken (2018) presented above.

The formation of habits is often, at first, motivated by peoples' deliberate choice to achieve specific goals (Wood and Rünger 2016). For example, an intention to floss can lead to the habit of flossing after teeth brushing (Judah et al. 2013). However, we may also develop many habits from behaviours we do not necessarily intend to do. For example, a lack of available public transportation can push a habit of car commuting regardless of preferences and a tight budget can form dietary habits around cheaper less nutritious food. People even develop habits for maladaptive behaviours that they explicitly intend not to do, such as procrastination or nail-biting (Verhoeven and de Wit 2018) and can fall into the habits of not doing something (however, these kinds of habits are less explored in the literature; Verplanken 2018).

The creation of habits is a repetitive process that gradually strengthens an association between a specific context and a behavioural response. With time, the reward that follows an action will be activated not by the action itself but by contextual cues (Wood and Rünger 2016). This habit formation process is sometimes conceptualized by "the habit loop" (see Fig. 1).

The importance of repetition in habit creation was illustrated in a study by Lally et al. (2010) in which repetitions of simple health behaviours (e.g. walking after dinner) required from 18 to as many as 254 days in the same context to become habitual and be performed without thinking. Habits can also be clumped together and 


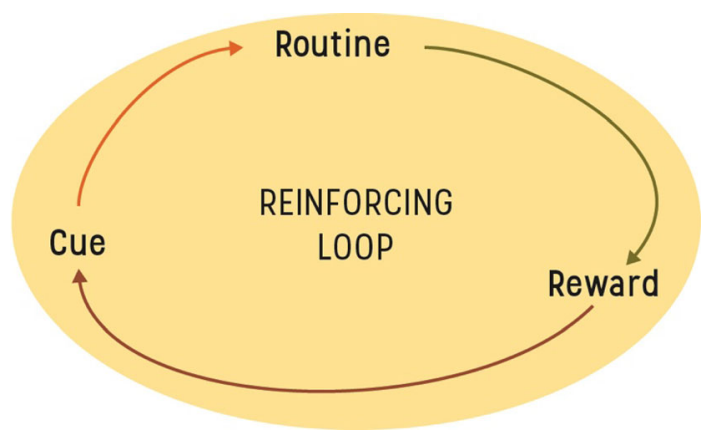

Fig. 1 The habit loop illustrating how a habit is gradually reinforcing a rewarding association between cue and action (modified from Duhigg 2012)

activated almost as one unit through a phenomenon called "habit scripts" (Verplanken et al. 1994; Orbell and Verplanken 2018). This can be seen as a habit domino sequence where one habit activates the next one (and might explain how you end up at work without really remembering how you got there). These scrips, or routines, can involve multiple actions and sequences. For example, a nightly 'dental care' routine can include tooth-brushing and flossing as two separate habitual patterns (Judah et al. 2013). Although situations never completely map onto earlier experiences, research on transfer learning and stimulus generalization has shown that behavioural responses replicate quickly when the current environment is similar enough to the one in which the behaviour was previously performed (Bouton et al. 1999).

Context plays an important part in habit theory. Not only does the physical and social environment frame the range of possible actions and heavily steer habits creation, the context we repeatedly find ourselves in will with time contain numerous cues that activate behaviours we execute without much conscious oversight (Neal et al. 2012). Contextual cues are powerful drivers of behaviour and can include features of the physical environment, other individuals, emotions or preceding actions in a sequence (Wood and Rünger 2016). People can easily fall back on doing unwanted behaviours in a context with established contextual cues that they would not do in a context without the cues. Neal et al. (2011) highlighted this phenomenon in an ingenious experiment where they showed how some participants would eat stale, 1-week-old, popcorn at the cinema, but other participants would not eat similarly old popcorn in a meeting room, presumably because contextual cues for popcorn-eating was present in the former scenario but not the latter. Because people's habits mainly operate by mechanisms they are not aware of, they tend to "own" their habits, and to describe them as intentional, particularly, if the habits are positive (Verplanken and Orbell 2003; Mazar and Wood 2018; Verplanken and Sui 2019). Research has shown that people often use post hoc justification for their habits. For example, we tend to make up reasons for unexplained automatic behaviour that align with our current values and goals (Adriaanse et al. 2018) and Neal et al. (2012) showed in an experiment that strong habits often were perceived as purposeful goal-directed behaviour, but were actually driven by recurring contextual triggers. Similar post hoc justifications for behaviour are also highlighted in cognitive dissonance theory which shows our tendency to justify actions when they are contradictory to our beliefs to reduce feelings of discomfort (Festinger 1962).

\section{Ways to break or create habits}

There are several ways to break old or create new habits to be found in the literature. Some techniques help people adopt particular behaviours and allow people to act in intentional ways, while others assist the breaking of unwanted habits and help establish personal control over behaviour. We list some of the more prevalent ones below.

\section{Implementation intention}

Implementation intention is a strategy developed to bridge the intention-behaviour gap. It is an action plan approach to achieve pre-selected goal-directed actions. An implementation-intention strategy is used through committing to an ifthen structure, i.e. "when situation $\mathrm{X}$ arises, I will perform response Y" (Gollwitzer and Sheeran 2006). The goal of the strategy is to have contextual cues activate an automatic behavioural response. If successful, the desired behaviour will occur without hesitation or deliberation in a pre-determined situation. Once the behaviour is set, through enough behavioural repetition, it may continue to operate as a new desired habit. Implementation intention can be used to promote new behaviours as well as breaking old habits, as it has proven successful in e.g. increasing consumption of organic food (Bamberg 2002) and recycling rates (Holland et al. 2006). Notably, implementation-intention strategies have shown an overall medium-to-large effect magnitude $(d=0.65)$ across 94 independent studies (Gollwitzer and Sheeran 2006).

\section{Self-monitoring and cue identification}

Because contextual cues automatically activate behaviour responses, careful self-monitoring and conscious inhibition of the action when it is activated in memory can be crucial in efforts to break free from unwanted habits. Quinn et al. (2010) showed that thinking phrases like "don't do it" when an unwanted action response was about to occur was essential for controlling strong habits. Reflecting upon which situations habits occur in and identifying what internal and situational factors cue the habit through "cuemonitoring" have been shown to be effective in breaking 
unwanted habits such as unhealthy snacking (Verhoeven et al. 2014). Similarly, habit reversal training, a clinical behavioural treatment for harmful habits focuses on identifying the cue (specifically the sensation occurring just after the cue has been triggered) and replacing the cuebehaviour association with a competing behavioural response. The goal of the treatment is to alter the habit loop and link a more desirable behaviour to the already-established cue. This strategy has been successful in treating various damaging habits such as tic disorders and Tourette syndrome (Piacentini and Chang 2005; Fründt et al. 2017).

\section{Habit discontinuity hypothesis}

The habit discontinuity hypothesis poses that context change can offer an opportunity to break old and create new habits in situations where people free themselves from environmental cues that activate unwanted responses (Verplanken et al. 2008). Major discontinuities can be transitioning to new phases in life (e.g. from education to a job), geographical or physical changes (e.g. residential or work-related relocations), or changes in the environment where habits are executed (e.g. infrastructural changes). Initial empirical research supports this hypothesis and interventions to change seem to be more effective after relocation when habits momentarily "un-freeze" (Verplanken and Roy 2016).

\section{THREE ARGUMENTS FOR STUDYING PRO- ENVIRONMENTAL HABITS}

It is made abundantly clear within the habit literature that our past behaviour is a strong predictor of future behaviour (e.g. Ouellette and Wood 1998; Sutton and Sheeran 2003). From a sustainability perspective, this does not bode well since many of our past behaviours support the unsustainable trajectory we currently find ourselves on. To ensure a sustainable future, we need to better understand the pull of our past decisions and explore the role of habits within research on sustainability transformations. This means both understanding how to break out of environmentally damaging behaviour patterns and how to establish new PEH. Below we present three arguments, showcasing the importance of looking at sustainable behaviours through a habit lens.

\section{Habit theory highlights how behaviour is heavily reliant on automatic processes}

Habit theory highlights how our behaviour is heavily reliant on automatic processes, something often left out in sustainability narratives and in policy advice, as well as in pro-environmental research. A PEH approach would showcase how behaviour is heavily influenced by both deliberate and impulsive processes and how these interact. A habit perspective could situate sustainable actions as a part of a larger set of automatic actions and thoughts, pushing research and interventions beyond focussing on intrinsic motivation and reasoned behaviour alone.

Sustainability interventions that utilize our tendency to depend on the impulsive, automatic system can be effective tools for promoting certain sustainable behaviours. This perspective is exemplified in the behavioural economics literature that focuses on 'nudges'. This research explores how automatic processes influence and guide behaviour more broadly e.g. how heuristics (cognitive rules of thumb), norms, information framing, loss aversion, and social pressure influence our choices and proposes interventions in alignment with automatic responses to encourage certain behaviours (Thaler and Sunstein 2008). Nudges have been successfully applied for triggering some shifts towards pro-environmental behaviours, for example, reducing water and paper consumption (Egebark and Ekström 2016), increasing food waste recycling (Linder et al. 2018), lowering energy use (Allcott and Mullainathan 2010; Allcott 2011; Costa and Kahn 2013; Allcott and Rogers 2014), and limiting food waste (Kallbekken and Sælen 2013). Similarly, a meta-analysis found that norms queued by the environment often result in automatic behaviour response and that such implicitly cued norms had a stronger impact on behaviour than explicitly stated norms (Bergquist et al. 2019). This was argued to be because implicit norms were less likely to result in anticonformity responses such as psychological reactance when the behavioural response happens without conscious processing. Although nudges and norms are distinctly different from habits, these findings highlight the potential of interventions targeting automatic processes to promote proenvironmental behaviour changes. However, as nudge interventions are not always easy to implement (Ridder et al. 2020), research on PEH could move beyond 'simple nudge approaches' to a more holistic understanding of behaviour change. For example, a better understanding of habit theory can help tailor interventions so they are suitable for targeting different behaviours (Verplanken and Wood 2006). Less established or new behaviours, not bound by automatic processes, might align more easily with intentions and could therefore be targeted by more conventional attitude/intention building approaches (Dahlstrand and Biel 1997; Klöckner 2013). Routine behaviours that are guided by automatic processes might, however, demand interventions that account for habit breaking in order to change. PEH can guide the designing of interventions for pro-environmental behaviours by utilizing the already existing tools for breaking and creating habits (see the examples given in Sect. 2.5). On the whole, 
an important realization in the quest for sustainable change is that stronger interventions that account for habit breaking might be an essential, and currently underutilized, addition in order to address the automatic aspect of behaviour when aiming for urgently needed behaviour changes on the societal scale level.

\section{Environmental context sets boundary conditions for behaviour and shapes habits}

Even though the environmental context is emphasized in habit theory, it is often overlooked in the literature on proenvironmental behaviour (Sörqvist 2016). This is a major shortcoming. Physical and social environmental conditions motivate and constrain actions through the range of behaviours they allow and enable. In order for any habit to develop, the possibility for that habit needs to be provided by the surrounding context. In ecological psychology, this range of possible behaviours is conceptualized as relations between features of the environment and abilities of the agent, also known as 'affordances' (Chemero 2003; Withagen et al. 2012). Sustainable behaviours have to be understood as part of the range of possible behaviours that the environment enables, for environmental attitudes and behaviour to align (Kaaronen 2017). And if a pro-environmental behaviour is made to be the easiest option, behaviour is likely to follow-regardless of values or intentions (Linder et al. 2021).

The habit literature highlights our tendency to develop habits when performing reoccurring actions in stable contexts (e.g. Gardner 2015; Wood \& Rünger 2016), and that behaviour is heavily driven by context-specific cues after habits have been set. Together, this is making the environmental context a powerful leverage point for understanding and encouraging $\mathrm{PEH}$. Considering that intrinsic motivation tends to fluctuate over time, a stable environmental context that supports reoccurring pro-environmental actions could be essential for the development of PEH. Furthermore, focussing on the behaviours we repeat in recurring contexts could increase understanding of inertia towards sustainable behaviour change, as habit theory highlights: it can be difficult to change behaviour in familiar contexts. Hence, reaching sustainability goals can be an uphill battle in conflict with everyday environments that automatically activate old unsustainable actions. This is exemplified by the above-mentioned habit discontinuity hypothesis, and mounting evidence supports this hypothesis in relation to pro-environmental behaviour. For example, university employees concerned about the environment who had recently moved house were commuting more sustainably than those who were equally concerned but had not relocated (Verplanken et al. 2008) and interventions to promote sustainable behaviours were more effective among newly moved participants (Verplanken and Roy 2016), suggesting that a change of context can provide an opportunity to more easily act on environmental values. Looking at sustainable behaviours through a habit lens would automatically link behaviour to the physical environment which might be needed to build an understanding of how sustainable behaviours are formed and steered by their surrounding context.

\section{Our habits and past behaviour shape our values and self-identity}

A PEH research agenda would not only acknowledge that our past behaviour is a strong predictor of future action, but also that our habits could influence how we perceive ourselves, our values, beliefs, and self-identity. Recent studies have explored habits' role in our identity and found that they may serve to define who we are (Verplanken and Orbell 2003; Verplanken and Sui 2019). By looking at their frequent behaviours people may label themselves as "the type of person that does X" (e.g. recycle, or buy organic food; Gardner et al. 2012) and infer that it is an important part of their identity. This aligns with self-perception theory that argues that we sometimes determine our attitudes and preferences by interpreting our actions (Bem 1972). Hence, a PEH lens on behaviour could contrast the assumptions made in the somewhat linear attitude-behaviour models by focussing on the feedback loop from behaviour back to attitudes (see Fig. 2). This amounts to conceptually flipping the models, highlighting how past behaviour and habits influence e.g. intentions and intrinsic motivation, and how habits, intention, and motivation coevolve. PEH have been shown to correlate with biospheric values and norms (e.g. Verplanken and Roy 2016), although more research is needed to untangle the directions of causal relationships. Related research has shown some

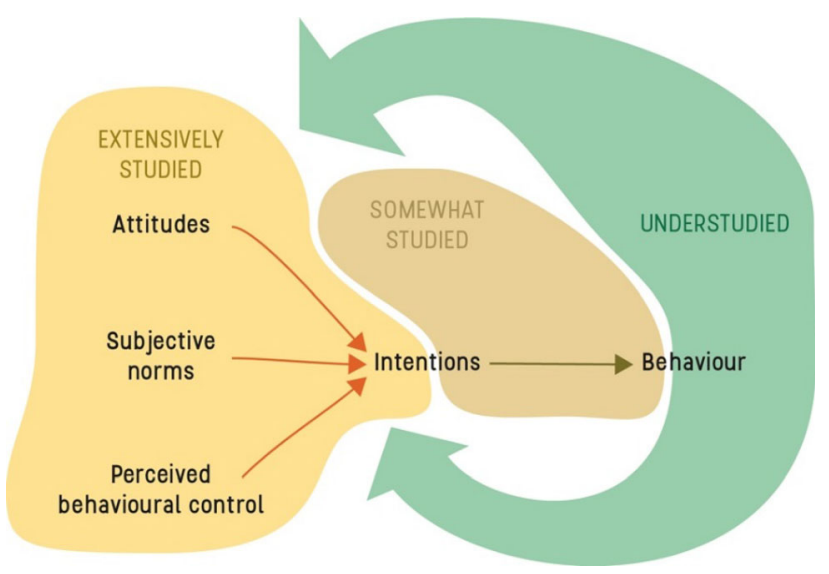

Fig. 2 Visualizing the perceived research gap using the theory of planned behaviour as an example. Showcasing how $\mathrm{PEH}$ can complement the dominating models and narrative 
support for the importance of the feedback loop from behaviour to attitude. For example, Giusti et al. (2014) explored how physical access to nature experiences ensured a reoccurring interaction with nature that was shown to correlate with environmental awareness and sensitivity. Nature routines are an essential component to develop a meaningful relationship with nature (Giusti et al. 2018), which is true for intentional as much as incidental nature experiences (Beery et al. 2017). It has also been shown how personal experience with climate change increases intentions to act pro-environmentally (Broomell et al. 2015). Furthermore, a longitudinal study with 10-year-old children participating in a nature conservation project indicated that actively protecting endangered species can shape children's connectedness with nature (Barthel et al. 2018). The above findings are not necessarily related to the developments of habits (although they certainly could be), other factors such as socialization (Klöckner and Matthies 2012) and social influence (Cialdini and Goldstein 2004) could be important factors in explaining how such activities influence our identity. But they showcase how our past behaviour and routines could be an important part of the development of sustainable values and identities. We believe that a PEH approach could be an important component to further explore this feedback loop from past behaviour, experiences, and habit to sustainable attitudes, values, and self-identity.

\section{FUTURE OUTLOOK: EXPLORING HABITS' ROLE IN SUSTAINABILITY TRANSFORMATIONS}

Below we highlight some particularly promising research avenues and ways of applying PEH to advance the science on sustainable transformations based on the arguments presented above.

\section{Habit architecture-design urban environments to transform habits}

Context is the invisible force that help creat and mentain habits. The immediate social and physical environment surrounding the individual sets boundaries for behaviours and can overpower people's ability to act in line with proenvironmental values. As we develop habits by performing reoccurring actions in stable contexts, the behaviours these 'stable contexts' support or discourage are likely to heavily steer the creation of habits. Hence, careful design of everyday environments could greatly influence what kind of habits people will develop. Habit architecture (coined by Orbell and Verplanken 2018), i.e. promoting desired habits through careful design, seems especially important when considering the construction of projected new urban environments for roughly 2.5 billion people globally between 2010 and 2050 (United Nations 2014). Planning and carefully designing these new human habitats to promote PEH strikes us as a pragmatic leverage point in efforts to foster large-scale sustainability transformations. The habit discontinuity hypothesis (Verplanken et al. 2008) further highlights how these new constructions and urban landscapes might be seized upon as the basis of cost-effective opportunities to create PEH in new environments where people are more inclined to change (Verplanken and Roy 2016). If successful, PEH could become part of urban lifestyles that go in line with global sustainability goals. For example, habit architecture could be especially suitable for promoting transformations in mobility and commuting behaviour (Kaaronen and Strelkovskii 2020) and consumption habits (Wiedmann et al. 2020). These behaviours provide an intuitive example of applying a habit architecture since commuting travel (e.g. travelling to work) and everyday consumption (e.g. shopping at the local grocery store) is performed regularly in stable contexts and therefore likely lead to the development of habits. It has been shown that the extent to which daily transportation is carried out by walking or biking varies from less than $10 \%$ to more than $50 \%$ between cities of OECD countries (Buehler et al. 2017). A meta-analysis of 23 studies found the simple existence of sidewalks or footpaths to be the one factor most tightly coupled with walking behaviour (Wang et al. 2016). Suffice to say, proenvironmental attitudes only matter for travel behaviour insofar as the environment permits acting on them (Árnadóttir et al. 2019). Of course, the enabling of these proenvironmental behaviours does not guarantee habit formation. But it is safe to say that a context that enables and promotes sustainable actions would provide a good foundation for the development of PEH. An illustrative example is Copenhagen, a city that has witnessed a biking revolution in recent decades that is largely attributed to an increase in affordances for cycling, like cycling tracks, bicycle parking opportunities, bridges, and public bicycle schemes in parallel with policy for a cycling-friendly urban environment (Kaaronen and Strelkovskii 2020). In the 1960s, car use rapidly surpassed the use of bicycles in Copenhagen. However, a renaissance of the bicycle grew throughout the 1980s and 1990s. Recently, cycling represented $50 \%$ of all transport in the city while numbers of seriously injured or killed cyclists were decreasing. The increase in biking affordances in Copenhagen enabled proenvironmental cycling behaviour, whereby people developed stronger cycling habits, which in turn created a demand for the construction of more pro-environmental affordances for cycling. Such reinforcing feedback dynamics can lead to swift collective changes in behaviour once a critical threshold is passed (Kaaronen and 
Strelkovskii 2020). Thus, this indicates that tipping points in collective PEH formation could be efficiently triggered by changes in the physical urban form. Walking and biking are also promoted by making environments harder to drive in. Five cities in Germany, Austria, and Switzerland have witnessed reduced car share of trips through mutually reinforcing interventions like car-free pedestrian zones, shared streets with lower speed limits or wider sidewalks (Buehler et al. 2017). Crucially, behavioural change in all these cities has followed mainly from interventions in the physical environment, highlighting how habit architecture could complement interventions that appeal to people's intentions or motivations to promote recurring sustanible actions.

\section{Pro-environmental habits to foster intrinsic motivation and sustainable cultures}

A PEH approach might not only be an underutilized way to spur behaviour change but could also be an effective way to promote pro-environmental attitudes, identities, and cultures. An illustrative example of how a change in habits influenced norms and attitudes could be seen after the smoking ban in bars that happened in England in 2007. Not only did it reduced smoking behaviour overall but also significantly increased anti-smoking norms and increased the perceived risks of smoking (Orbell et al. 2009). Ultimately, we find sufficient evidence to hypothesize that sucesfully promoting PEH and nature routines could trigger self-reinforcing feedbacks that promote both people's wellbeing (Giusti and Samuelsson 2020) and the psychological foundation of sustianable cultures (Giusti et al. 2014; Giusti 2019). Social-ecological systems research could address the issue of how to promote a co-evolution between PEH and environmentally conscious identities, especially among urban residents that are often psychologically disconnected from the Biosphere (Colding et al. 2020; Giusti et al. 2020). For instance, the research on urban stewardship may find novel empirical avenues on how habits and routines around actively caring for local ecosystems and species may co-evolve with intrinsic motivation (Andersson et al. 2017; Sanecka et al. 2020).

Another avenue that could be attractive for future research is to further explore how interventions that are already commonly used to break unhealthy habits (e.g. tobacco smoking, unhealthy diets, gambling) could be used for breaking recurring environmentally degrading behaviours. Lastly, when designing for $\mathrm{PEH}$, sustainable behaviours need to be part of the range of possible behaviours the environment enables (Kaaronen 2017) and preferably be the easier ones to perform (Rosenthal and Linder 2021) and we see the need for novel research on how to ensure that pro-environmental motivations and attitudes are not overridden by repressive environmental features, preventing new PEH to form. Longitudinal studies following up on habit architecture and interventions, to explore when and if PEH develops could prove essential for building understanding on how to promote widespread sustainable habits that last over time-without effort and deliberation.

Acknowledgements Linder's and Samuelsson's work is enabled by the University of Gävle and funds from FORMAS/The Swedish Research Council for Environment, Agricultural Sciences and Spatial Planning. The FORMAS project is called Spatial and Experiential Analyses for Urban Social Sustainability (ZEUS) (Reference Number: 2016-01193). Barthel's work is funded by Kunskapsstiftelsen; Future Proof Cities, the Mistra and Formas Program called FAIRTRANS, and by Stockholm Resilience Centre. Giusti is supported by Vinnova project called BIG (2013-02328).

Funding Open access funding provided by University of Gävle.

Open Access This article is licensed under a Creative Commons Attribution 4.0 International License, which permits use, sharing, adaptation, distribution and reproduction in any medium or format, as long as you give appropriate credit to the original author(s) and the source, provide a link to the Creative Commons licence, and indicate if changes were made. The images or other third party material in this article are included in the article's Creative Commons licence, unless indicated otherwise in a credit line to the material. If material is not included in the article's Creative Commons licence and your intended use is not permitted by statutory regulation or exceeds the permitted use, you will need to obtain permission directly from the copyright holder. To view a copy of this licence, visit http://creativecommons. org/licenses/by/4.0/.

\section{REFERENCES}

Aboelmaged, M. 2021. E-waste recycling behaviour: An integration of recycling habits into the theory of planned behaviour. Journal of Cleaner Production 278: 124182.

Adriaanse, M.A., F.M. Kroese, J. Weijers, P.M. Gollwitzer, and G. Oettingen. 2018. Explaining unexplainable food choices. European Journal of Social Psychology 48: O15-O24.

Allcott, H. 2011. Social norms and energy conservation. Journal of Public Economics 95: 1082-1095. https://doi.org/10.1016/j. jpubeco.2011.03.003.

Allcott, H., and S. Mullainathan. 2010. Behavior and energy policy. Science 327: 1204-1205.

Allcott, H., and T. Rogers. 2014. The short-run and long-run effects of behavioral interventions: Experimental evidence from energy conservation. The American Economic Review 104: 3003-3037.

Andersson, E., J. Enqvist, and M. Tengö. 2017. 12 Stewardship in urban landscapes. In The science and practice of landscape stewardship, ed. C. Bieling and T. Plieninger, 222. Cambridge: Cambridge University Press.

Árnadóttir, Á., M. Czepkiewicz, and J. Heinonen. 2019. The geographical distribution and correlates of pro-environmental attitudes and behaviors in an urban region. Energies 12: 1540.

Bamberg, S. 2002. Implementation intention versus monetary incentive comparing the effects of interventions to promote the purchase of organically produced food. Journal of Economic Psychology 23: 573-587. 
Barthel, S., S. Belton, C.M. Raymond, and M. Giusti. 2018. Fostering children's connection to nature through authentic situations: The case of saving salamanders at school. Frontiers in Psychology 9: 928.

Beery, T.H., C.M. Raymond, M. Kyttä, A.S. Olafsson, T. Plieninger, M. Sandberg, M. Stenseke, M. Tengö, et al. 2017. Fostering incidental experiences of nature through green infrastructure planning. Ambio 46: 717-730. https://doi.org/10.1007/s13280017-0920-Z

Bell, A.E., and K.R. Ulhas. 2020. Working to reduce food waste: Investigating determinants of food waste amongst Taiwanese workers in factory cafeteria settings. Sustainability 12: 9669.

Bem, D.J. 1972. Self-perception theory. Advances in Experimental Social Psychology 6: 1-62.

Bergquist, M., A. Nilsson, and W.P. Schultz. 2019. A meta-analysis of field-experiments using social norms to promote pro-environmental behaviors. Global Environmental Change 59: 101941.

Blake, J. 1999. Overcoming the 'value-action gap'in environmental policy: Tensions between national policy and local experience. Local Environment 4: 257-278.

Bouman, T., and L. Steg. 2019. Motivating society-wide proenvironmental change. One Earth 1: 27-30.

Bouton, M.E., J.B. Nelson, and J.M. Rosas. 1999. Stimulus generalization, context change, and forgetting. Psychological Bulletin 125: 171 .

Brondizio, E. S., J. Settele, S. Diaz, and H. T. Ngo. 2019. Global assessment report on biodiversity and ecosystem services of the Intergovernmental Science-Policy Platform on Biodiversity and Ecosystem Services. IPBES Secretariat, Bonn.

Broomell, S.B., D.V. Budescu, and H.-H. Por. 2015. Personal experience with climate change predicts intentions to act. Global Environmental Change 32: 67-73. https://doi.org/10.1016/j. gloenvcha.2015.03.001.

Buehler, R., J. Pucher, R. Gerike, and T. Götschi. 2017. Reducing car dependence in the heart of Europe: Lessons from Germany, Austria, and Switzerland. Transport Reviews 37: 4-28.

Chemero, A. 2003. An outline of a theory of affordances. Ecological Psychology 15: 181-195.

Chuang, L.-M., P.-C. Chen, and Y.-Y. Chen. 2018. The determinant factors of travelers' choices for pro-environment behavioral intention-integration theory of planned behavior, unified theory of acceptance, and use of technology 2 and sustainability values. Sustainability 10: 1869.

Cialdini, R.B., and N.J. Goldstein. 2004. Social influence: Compliance and conformity. Annual Review of Psychology 55: 591-621. https://doi.org/10.1146/annurev.psych.55.090902. 142015.

Çoker, E.N., and S. van der Linden. 2020. Fleshing out the theory of planned of behavior: Meat consumption as an environmentally significant behavior. Current Psychology. https://doi.org/10. 1007/s12144-019-00593-3.

Colding, J., M. Giusti, A. Haga, M. Wallhagen, and S. Barthel. 2020. Enabling relationships with nature in cities. Sustainability 12: 4394.

Costa, D.L., and M.E. Kahn. 2013. Energy conservation "nudges" and environmentalist ideology: Evidence from a randomized residential electricity field experiment. Journal of the European Economic Association 11: 680-702. https://doi.org/10.1111/jeea. 12011.

Dahlstrand, U., and A. Biel. 1997. Pro-environmental habits: Propensity levels in behavioral change 1. Journal of Applied Social Psychology 27: 588-601.

Dharmesti, M., B. Merrilees, and L. Winata. 2020. "I'm mindfully green": Examining the determinants of guest pro-environmental behaviors (PEB) in hotels. Journal of Hospitality Marketing \& Management 29: 830-847.
De Ridder, D., J. Feitsma, M. van den Hoven, F. Kroese, T. Schillemans, M. Verweij, T. Venema, A. Vugts, et al. 2020. Simple nudges that are not so easy. Behavioural Public Policy. https://doi.org/10.1017/bpp.2020.36.

Donald, I.J., S.R. Cooper, and S.M. Conchie. 2014. An extended theory of planned behaviour model of the psychological factors affecting commuters' transport mode use. Journal of Environmental Psychology 40: 39-48.

Edwards, T. 1891. A dictionary of thoughts: Being a cyclopedia of laconic quotations from the best authors, both ancient and modern. New York: Cassell Publishing Company.

Egebark, J., and M. Ekström. 2016. Can indifference make the world greener? Journal of Environmental Economics and Management 76: $1-13$.

Epstein, S. 1994. Integration of the cognitive and the psychodynamic unconscious. American Psychologist 49: 709.

Festinger, L. 1962. A theory of cognitive dissonance, vol. 2. Palo Alto: Stanford University Press.

Flynn, C., Yamasumi, E., Fisher, S., Snow, D., Grant, Z., Kirby, M., Browning, P., Rommerskirchen, M. et al. 2021. Peoples' climate vote: Results. United Nations Development Programme and University of Oxford. https://www.undp.org/publications/ peoples-climate-vote. Accessed 31 July, 2021.

Fründt, O., D. Woods, and C. Ganos. 2017. Behavioral therapy for Tourette syndrome and chronic tic disorders. Neurology Clinical Practice 7: 148-156.

Gardner, B. 2015. A review and analysis of the use of 'habit'in understanding, predicting and influencing health-related behaviour. Health Psychology Review 9: 277-295.

Gardner, B., G. de Bruijn, and P. Lally. 2012. Habit, identity, and repetitive action: A prospective study of binge-drinking in UK students. British Journal of Health Psychology 17: 565-581.

Giusti, M. 2019. Human-nature relationships in context. Experiential psychological and contextual dimensions that shape children's desire to protect nature. PLOS ONE 14: e0225951. https://doi. org/10.1371/journal.pone.0225951.

Giusti, M., and K. Samuelsson. 2020. The regenerative compatibility: A synergy between healthy ecosystems, environmental attitudes, and restorative experiences. PLOS ONE 15: e0227311.

Giusti, M., S. Barthel, and L. Marcus. 2014. Nature routines and affinity with the biosphere: A case study of preschool children in Stockholm. Children Youth and Environments 24: 16-42.

Giusti, M., U. Svane, C.M. Raymond, and T.H. Beery. 2018. A framework to assess where and how children connect to nature. Frontiers in Psychology 8: 2283.

Giusti, M., W. Wang, and T. Marriott. 2020. Connecting land. A transdisciplinary workshop to envision a nature-connecting human habitat. Cities \& Health. https://doi.org/10.1080/ 23748834.2020.1742491.

Gollwitzer, P.M., and P. Sheeran. 2006. Implementation intentions and goal achievement: A meta-analysis of effects and processes. Advances in Experimental Social Psychology 38: 69-119.

Heidbreder, L.M., J. Steinhorst, and M. Schmitt. 2020. Plastic-free July: An experimental study of limiting and promoting factors in encouraging a reduction of single-use plastic consumption. Sustainability 12: 4698.

Holland, R.W., H. Aarts, and D. Langendam. 2006. Breaking and creating habits on the working floor: A field-experiment on the power of implementation intentions. Journal of Experimental Social Psychology 42: 776-783. https://doi.org/10.1016/j.jesp. 2005.11.006.

Huang, L., Y. Wen, and J. Gao. 2020. What ultimately prevents the pro-environmental behavior? An in-depth and extensive study of the behavioral costs. Resources, Conservation and Recycling 158: 104747. 
IPCC. 2014. Climate change 2014: synthesis Report. Contribution of working groups I, II and III to the fifth assessment report of the intergovernmental panel on climate change. IPCC.

Jackson, T. 2004. Motivating sustainable consumption. A review of evidence on consumer behaviour and behavioural change In: $A$ report to the Sustainable Development Research Network, as part of the ESRC Sustainable Technologies Programme, Centre for Environmental Strategy, University of Surrey, Guildford.

Judah, G., B. Gardner, and R. Aunger. 2013. Forming a flossing habit: An exploratory study of the psychological determinants of habit formation. British Journal of Health Psychology 18: 338-353.

Kaaronen, R.O. 2017. Affording sustainability: Adopting a theory of affordances as a guiding heuristic for environmental policy. Frontiers in Psychology 8: 1-13. https://doi.org/10.3389/fpsyg. 2017.01974.

Kaaronen, R.O., and N. Strelkovskii. 2020. Cultural evolution of sustainable behaviors: Pro-environmental tipping points in an agent-based model. One Earth 2: 85-97.

Kallbekken, S., and H. Sælen. 2013. "Nudging" hotel guests to reduce food waste as a win-win environmental measure. Economics Letters 119: 325-327. https://doi.org/10.1016/j. econlet.2013.03.019.

Klöckner, C.A. 2013. A comprehensive model of the psychology of environmental behaviour-A meta-analysis. Global Environmental Change 23: 1028-1038.

Klöckner, C.A., and E. Matthies. 2012. Two pieces of the same puzzle? Script-based car choice habits between the influence of socialization and past behavior 1. Journal of Applied Social Psychology 42: 793-821.

Kollmuss, A., and J. Agyeman. 2002. Mind the Gap: Why do people act environmentally and what are the barriers to pro-environmental behavior? Environmental Education Research 8: 239-260. https://doi.org/10.1080/13504620220145401.

Kurz, T., B. Gardner, B. Verplanken, and C. Abraham. 2015. Habitual behaviors or patterns of practice? Explaining and changing repetitive climate-relevant actions. Wiley Interdisciplinary Reviews: Climate Change 6: 113-128.

Lally, P., C.H.M. Van Jaarsveld, H.W.W. Potts, and J. Wardle. 2010. How are habits formed: Modelling habit formation in the real world. European Journal of Social Psychology 40: 998-1009.

Linder, N., T. Lindahl, and S. Borgström. 2018. Using behavioural insights to promote food waste recycling in urban householdsEvidence from a longitudinal field experiment. Frontiers in Psychology 9: 1-13. https://doi.org/10.3389/fpsyg.2018.00352.

Linder, N., S. Rosenthal, P. Sörqvist, and S. Barthel. 2021. Internal and external factors' influence on recycling: Insights from a laboratory experiment with observed behavior. Frontiers in Psychology 12: 699410. https://doi.org/10.3389/fpsyg.2021.699410.

Liu, A., E. Ma, H. Qu, and B. Ryan. 2020. Daily green behavior as an antecedent and a moderator for visitors' pro-environmental behaviors. Journal of Sustainable Tourism 28: 1390-1408.

Manfredo, M.J., T.L. Teel, R.E.W. Berl, J.T. Bruskotter, and S. Kitayama. 2020. Social value shift in favour of biodiversity conservation in the United States. Nature Sustainability 4: 323-330.

Mazar, A., and W. Wood. 2018. Defining habit in psychology. In The psychology of habit, ed. B. Verplanken, 13-29. Cham: Springer.

McEachan, R., N. Taylor, R. Harrison, R. Lawton, P. Gardner, and M. Conner. 2016. Meta-analysis of the reasoned action approach (RAA) to understanding health behaviors. Annals of Behavioral Medicine 50: 592-612.

Miller, K.J., A. Shenhav, and E.A. Ludvig. 2019. Habits without values. Psychological Review 126: 292.

Neal, D.T., W. Wood, J.S. Labrecque, and P. Lally. 2012. How do habits guide behavior? Perceived and actual triggers of habits in daily life. Journal of Experimental Social Psychology 48: 492-498.
Neal, D.T., W. Wood, M. Wu, and D. Kurlander. 2011. The pull of the past: When do habits persist despite conflict with motives? Personality and Social Psychology Bulletin 37: 1428-1437.

Orbell, S., and B. Verplanken. 2018. Progress and prospects in habit research. In The psychology of Habit, 397-409, ed. B. Verplanken. Cham: Springer.

Orbell, S., P. Lidierth, C.J. Henderson, N. Geeraert, C. Uller, A.K. Uskul, and M. Kyriakaki. 2009. Social-cognitive beliefs, alcohol, and tobacco use: A prospective community study of change following a ban on smoking in public places. Health Psychology 28: 753.

Ouellette, J.A., and W. Wood. 1998. Habit and intention in everyday life: The multiple processes by which past behavior predicts future behavior. Psychological Bulletin 124: 54.

Peattie, K. 2010. Green consumption: Behavior and norms. Annual Review of Environment and Resources 35: 195-228.

Piacentini, J., and S. Chang. 2005. Habit reversal training for tic disorders in children and adolescents. Behavior Modification 29: 803-822.

Quinn, J.M., A. Pascoe, W. Wood, and D.T. Neal. 2010. Can't control yourself? Monitor those bad habits. Personality and Social Psychology Bulletin 36: 499-511.

Rebar, A.L., B. Gardner, R.E. Rhodes, and B. Verplanken. 2018. The measurement of habit. In The psychology of habit, ed. B. Verplanken, 31-49. New York: Springer.

Ro, M., M. Brauer, K. Kuntz, R. Shukla, and I. Bensch. 2017. Making Cool Choices for sustainability: Testing the effectiveness of a game-based approach to promoting pro-environmental behaviors. Journal of Environmental Psychology 53: 20-30.

Rosenthal, S., and N. Linder. 2021. Effects of bin proximity and informational prompts on recycling and contamination. Resources Conservation and Recycling 168: 105430.

Russell, S.V., and C. Knoeri. 2020. Exploring the psychosocial and behavioural determinants of household water conservation and intention. International Journal of Water Resources Development 36: 940-955.

Sanecka, J., S. Barthel, and J. Colding. 2020. Countryside within the city: A motivating vision behind civic green area stewardship in Warsaw, Poland. Sustainability 12: 2313.

Schultz, P.W., and F.G. Kaiser. 2012. Promoting pro-Environmental Behavior. https://doi.org/10.1093/oxfordhb/9780199733026.013. 0029.

Sellberg, M.M., S.T. Borgström, A.V. Norström, and G.D. Peterson. 2017. Improving participatory resilience assessment by crossfertilizing the Resilience Alliance and Transition Movement approaches. Ecology and Society 22: 28.

Sörqvist, P. 2016. Grand challenges in environmental psychology. Frontiers in Psychology 7: 583.

Southerton, D. 2013. Habits, routines and temporalities of consumption: From individual behaviours to the reproduction of everyday practices. Time \& Society 22: 335-355.

Staats, H., P. Harland, and H.A.M. Wilke. 2004. Effecting durable change: A team approach to improve environmental behavior in the household. Environment and Behavior 36: 341-367.

Steffen, W., K. Richardson, J. Rockström, S.E. Cornell, I. Fetzer, E.M. Bennett, R. Biggs, S.R. Carpenter, et al. 2015. Planetary boundaries: Guiding human development on a changing planet. Science 347: 1259855.

Steg, L., and C. Vlek. 2009. Encouraging pro-environmental behaviour: An integrative review and research agenda. Journal of Environmental Psychology 29: 309-317. https://doi.org/10. 1016/j.jenvp.2008.10.004.

Strack, F., and R. Deutsch. 2004. Reflective and impulsive determinants of social behavior. Personality and Social Psychology Review 8: 220-247. 
Sutton, S., and P. Sheeran. 2003. Meta-analysis of the theory of planned behaviour and past behaviour. UK: University of Cambridge.

Thaler, R.H., and C.R. Sunstein. 2008. Nudge: Improving decisions about health, wealth, and happiness. Yale University Press.

UN General Assembly. 2015. Transforming our world: The 2030 agenda for sustainable development. New York: United Nations.

United Nations. 2014. World urbanization prospects. World urbanization prospects: Highlights 28. United Nations New York, USA.

Verhoeven, A., and S. de Wit. 2018. The role of habits in maladaptive behaviour and therapeutic interventions. In The psychology of habit, 285-303. New York: Springer.

Verhoeven, A.A.C., M.A. Adriaanse, E. de Vet, B.M. Fennis, and D.T.D. de Ridder. 2014. c 'if'for 'if-then'plans: Combining implementation intentions with cue-monitoring targeting unhealthy snacking behaviour. Psychology \& Health 29: $1476-1492$.

Verplanken, B. 2018. Introduction. In The psychology of habit: Theory, Mechanisms, Change, And Contexts, ed. B. Verplanken, 1-10. Cham: Springer.

Verplanken, B., and H. Aarts. 1999. Habit, attitude, and planned behaviour: Is habit an empty construct or an interesting case of goal-directed automaticity? European Review of Social Psychology 10: 101-134.

Verplanken, B., and S. Orbell. 2003. Reflections on past behavior: A self-report index of habit strength 1. Journal of Applied Social Psychology 33: 1313-1330.

Verplanken, B., and D. Roy. 2016. Empowering interventions to promote sustainable lifestyles: Testing the habit discontinuity hypothesis in a field experiment. Journal of Environmental Psychology 45: 127-134. https://doi.org/10.1016/j.jenvp.2015. 11.008 .

Verplanken, B., and J. Sui. 2019. Habit and identity: Behavioral, cognitive, affective, and motivational facets of an integrated self. Frontiers in Psychology 10: 1504.

Verplanken, B., and W. Wood. 2006. Interventions to break and create consumer habits. Journal of Public Policy \& Marketing 25: $90-103$.

Verplanken, B., H. Aarts, A. Knippenberg, and A. Moonen. 1998. Habit versus planned behaviour: A field experiment. British Journal of Social Psychology 37: 111-128.

Verplanken, B., H. Aarts, A. Van Knippenberg, and C. Van Knippenberg. 1994. Attitude versus general habit: Antecedents of travel mode choice. Journal of Applied Social Psychology 24: 285-300.

Verplanken, B., I. Walker, A. Davis, and M. Jurasek. 2008. Context change and travel mode choice: Combining the habit discontinuity and self-activation hypotheses. Journal of Environmental Psychology 28: 121-127.

Wang, Y., C.K. Chau, W.Y. Ng, and T.M. Leung. 2016. A review on the effects of physical built environment attributes on enhancing walking and cycling activity levels within residential neighborhoods. Cities 50: 1-15.

White, K., R. Habib, and D.J. Hardisty. 2019. How to SHIFT consumer behaviors to be more sustainable: A literature review and guiding framework. Journal of Marketing 83: 22-49.

Wiedmann, T., M. Lenzen, L.T. Keyßer, and J.K. Steinberger. 2020. Scientists' warning on affluence. Nature. Communications 11: $1-10$.

Winter, P.L., and S.M. Burn. 2010. Fostering sustainable operations in a natural resource management agency: Insights from the field. Journal of Forestry 108: 86-92.

Withagen, R., H.J. De Poel, D. Araújo, and G.-J. Pepping. 2012. Affordances can invite behavior: Reconsidering the relationship between affordances and agency. New Ideas in Psychology 30: 250-258.

Wood, W., and D. Rünger. 2016. Psychology of Habit. Annual Review of Psychology 67: 289-314. https://doi.org/10.1146/ annurev-psych-122414-033417.

Wood, W., J.M. Quinn, and D.A. Kashy. 2002. Habits in everyday life: Thought, emotion, and action. Journal of Personality and Social Psychology 83: 1281.

Wynes, S., K.A. Nicholas, J. Zhao, and S.D. Donner. 2018. Measuring what works: quantifying greenhouse gas emission reductions of behavioural interventions to reduce driving, meat consumption, and household energy use. Environmental Research Letters 13: 113002.

Publisher's Note Springer Nature remains neutral with regard to jurisdictional claims in published maps and institutional affiliations.

\section{AUTHOR BIOGRAPHIES}

Noah Linder $(\varangle)$ is a PhD student in Environmental Psychology at the University of Gävle. His research focusses on utilizing insights from psychology and behavioural economy to understand and promote pro-environmental behaviours.

Address: Department of Building Engineering, Energy Systems and Sustainability Science, University of Gävle, Kungsbäcksvägen 47, 80176 Gävle, Sweden.

e-mail: noah.linder@hig.se

Matteo Giusti is a researcher at the University of Gävle with a $\mathrm{PhD}$ in Sustainability Science from Stockholm Resilience Centre. His research interests include sustainability science, regenerative design, and people's connection with nature.

Address: Department of Building Engineering, Energy Systems and Sustainability Science, University of Gävle, Kungsbäcksvägen 47, 80176 Gävle, Sweden.

e-mail: matteo.giusti@hig.se

Karl Samuelsson is a $\mathrm{PhD}$ student in geospatial information science at University of Gävle. His research integrates perspectives from urban geography, environmental psychology, and social-ecological resilience, with a specific focus on how urban environments contribute to experiences that support or undermine individuals' wellbeing.

Address: Department of Building Engineering, Energy Systems and Sustainability Science, University of Gävle, Kungsbäcksvägen 47, 80176 Gävle, Sweden.

e-mail: karl.samuelsson@hig.se

Stephan Barthel is a highly cited professor in sustainability science (Web of science 2019, 2020). He holds a $\mathrm{PhD}$ in natural resource management from Stockholm Resilience Centre. He is the director of an interdisciplinary research program on urban sustainability at the University of Gävle. He is also co-director of FAIRTRANS which is a program on a fair transition to a fossil free society. His work is framed by complex adaptive systems and he likes to stimulate the integration of sustainability transformation research with socialecological resilience ranging in scale levels from individual behaviour and civic action to global governance.

Address: Department of Building Engineering, Energy Systems and Sustainability Science, University of Gävle, Kungsbäcksvägen 47, 80176 Gävle, Sweden.

Address: Stockholm Resilience Centre, Stockholm University, Stockholm, Sweden.

e-mail: Stephan.Barthel@hig.se 